\title{
BMJ Open How far do we still need to go? A survey on knowledge, attitudes, practice related to antimicrobial stewardship regulations among Chinese doctors in 2012 and 2016
}

Ruyu Xia, ${ }^{1}$ Xiaoyang Hu, ${ }^{2}$ Merlin Willcox, ${ }^{2}$ Xinxue $\mathrm{Li}^{3}{ }^{3}$ Yuxiu Li, ${ }^{4}$ Jian Wang, ${ }^{5}$ Xun Li, ${ }^{1}$ Michael Moore, ${ }^{2}$ Jianping Liu, ${ }^{1}$ Yutong Fei ${ }^{\circledR}$

To cite: Xia R, Hu X, Willcox M et al. How far do we still need to go? A survey on knowledge, attitudes, practice related to antimicrobial stewardship regulations among Chinese doctors in 2012 and 2016. BMJ Open 2019;9:e027687. doi:10.1136/ bmjopen-2018-027687

- Prepublication history and additional material for this paper are available online. To view these files, please visit the journal online (http://dx.doi. org/10.1136/bmjopen-2018027687).

$\mathrm{XH}$ and MW contributed equally.

Received 2 November 2018

Revised 5 April 2019

Accepted 15 May 2019

Check for updates

(C) Author(s) (or their employer(s)) 2019. Re-use permitted under CC BY-NC. No commercial re-use. See rights and permissions. Published by BMJ.

For numbered affiliations see end of article.

Correspondence to Professor Yutong Fei; feiyt@bucm.edu.cn

\section{ABSTRACT}

Objectives To explore doctors' knowledge, willingness, concerns and the countermeasures to the most stringent antimicrobial stewardship regulations of China which implemented in August 2012.

Design Cross-sectional survey. A pretested 32-point structured questionnaire was distributed to doctors by sending a web link via the mobile phone application WeChat through snowball sampling methods and email groups of medical academic societies.

Setting China.

Participants Doctors.

Primary and secondary outcome measures The questionnaire inquired about the doctors' experiences, knowledge, willingness, concerns and the countermeasures to the stewardship policies.

Results Total of persons in the groups was 19791 , among them 1194 submitted the answers, within them, 807 were doctors. Doctors had a mean age of 39.0 years. The majority $(78.9 \%$ in $2012,89.1 \%$ in 2016) reported that they were willing or very willing to accept the regulations. Almost all respondents $(93.2 \%)$ felt the stewardship regulations had the potential to adversely affect the prognosis of patients who would have been prescribed antimicrobials before they were implemented, and $>65 \%$ (65.7\% in $2012,66.9 \%$ in 2016 ) of doctors were often or always concerned about the prognosis of these patients. In $2012,32 \%$ of doctors prescribed restricted antimicrobials or suggested patient self-medication with restricted antimicrobials to address doctors' concerns, and this number decreased to $22.6 \%$ in 2016. Although compulsory antimicrobial stewardship training was frequent, less than half of respondents $(46.8 \%)$ responded correctly to all three knowledge questions.

Conclusion Antimicrobial stewardship regulations had some positive effect on rational antimicrobial use. Willingness and practice of doctors towards the regulations improved from 2012 to 2016 . Knowledge about rational antimicrobial use was still lacking. Doctors found ways of accessing restricted antibiotics to address their concerns about the prognosis of patients, which undermined the implementation of the stewardship regulations.
Strengths and limitations of this study

- The paper is the first to comprehensively explore doctors' feelings and attitudes towards the Chinese antimicrobial stewardship regulations.

- The survey recruited participants and administered the survey via WeChat, which is a convenient, time-saving and economic method to survey a diverse population. Our respondents covered 29 of 32 administrative divisions of mainland China.

- We cannot rule out a possible selection bias as our sample was not randomly selected. Although the snowball sampling method is effective and efficient when sampling from specific populations, participants who can be reached depend on the social connections of the key respondents.

- The proportion of completed questionnaires to all potential responders is low.

- Another limitation is the potential recall bias of information provided for year 2012 and 2016.

\section{INTRODUCTION}

The efficacy of antimicrobials is threatened by increasing levels of antimicrobial resistance. ${ }^{12}$ In 2014, it was estimated that China consumed 77760 tons of antimicrobial agents for humans and the defined daily doses per 1000 inhabitants per day were approximately six times larger than in the UK, USA, Canada and Europe. ${ }^{3}$

During the last decade, the Chinese Government has issued a series of healthcare regulations. $^{4-7}$ The 'administrative regulations for the clinical use of antimicrobials', implemented in August 2012, were the most stringent regulations ever (box 1). ${ }^{6}$ Several studies reported changes in the prescription rates of antibiotics to reflect the impact of the 2012 stewardship regulations, ${ }^{8-10}$ but we did not find any study which investigated the attitudes of Chinese doctors towards these regulations, although they might be an important barrier to implementation of the regulations. 
Box 1 Translated summary of 'administrative regulations for the clinical use of antimicrobials ${ }^{36}$

The administrative regulations for the clinical use of antimicrobials was issued and implemented by the National Health and Family Planning Commission (NHFPC, the former Ministry of Health).

\section{What are the regulations about?}

In the 2012 stewardship regulations, all hospitals in China were required to set up an antimicrobial agents administrative group or identify a point person to take control of antimicrobial stewardship. Infectious diseases departments and clinical microbial laboratories were required to be set up in all tertiary and secondary hospitals. Antibacterial agents were classified according to safety, efficacy, bacterial resistance, price and other factors. Prescribers have accredited prescription rights for different categories of antimicrobials, depending on their levels of seniority. Compulsory standardised trainings on the knowledge of clinical use of antimicrobials are required for all doctors.

\section{How was it supposed to be implemented or enforced? How was implementation monitored?}

NHFPC established the Centre for Antibacterial Surveillance and the China Antimicrobial Resistance Surveillance System to monitor the use of antibiotics and antibiotic resistance in hospitals. Surveillance systems within their respective administrative areas would be developed by local health administrative departments. The rankings of total usage of antimicrobials, classification of antimicrobials and percentage of prescriptions for antimicrobials in health facilities in their respective administrative regions are published and submitted to the higher authorities for the record. Managers of poorly performing health facilities are admonished. This is to ensure rational use of antimicrobial agents in healthcare settings.

\section{Were there any sanctions for not implementing it?}

Health facilities that fail to meet the requirements would be downgraded to a lower classification level. Doctors who fail to pass the exam of standard training or seriously violate the regulations can lose their accreditation to prescribe antibiotics, and/or have their professional qualification revoked. If doctors' actions led to serious consequences, they could be fined or prosecuted.

\section{Who was responsible for implementing it?}

NHFPC and local health administration investigate and reassign responsibility to hospital presidents or health facility management staff.

Our study aimed to explore knowledge, willingness, concerns and the countermeasures of doctors towards the most stringent antimicrobial stewardship regulations of China (2012) via a web-based survey. Specifically, we looked at: (1) what did they experience; (2) how good was their knowledge about prescribing antimicrobials; (3) what were their feelings (willingness/reluctance) towards the regulations (over a 5-year duration of implementation) when they were practicing; (4) what were the countermeasures, if any were used.

\section{METHODS}

\section{Survey recruitment}

A snowball sampling strategy, focus on recruiting docors practing in mainland China, was utilised. Participants were reached by the mobile phone Application (APP)
WeChat and emails. WeChat is currently the most widely used social media platform in China, with more than one billion users. ${ }^{11}$ Akin to a hybrid of Twitter, Facebook and WhatsApp, WeChat combines the functions of instant messaging, a blog and a social networking site. The invitations to participate in the survey were sent first to clinicians' WeChat groups by researchers, then they were cascaded by purposively inviting key respondents to send the link to their clinicians' WeChat groups in order to increase respondent sample size (WeChat groups details in online supplementary table S1). Email invitations were only sent to members of the World Federation of Chinese Medicine Societies. The professional occupation screening function was turned on therefore only those who identified themselves as doctors were able to proceed to the survey questions, others were directed politely to the end of the survey.

\section{Data collection}

The tool for collecting data is the questionnaire based in the WenJuanXing online survey service (English name 'SurveyStar', Changsha Ranxing Science and Technology, Shanghai, China), which is a online survey platform, akin to SurveyMonkey.

\section{Survey questionnaire}

The study was performed between 9 March to 30 March 2017 using a piloted 32-point structured questionnaire (see online supplementary table $\mathrm{S} 2^{12}$ ). The structured questionnaire consisted of questions about four categories of variables: (1) demographics and practice characteristics of the doctors; (2) implementation of the antimicrobial stewardship in healthcare facilities; (3) attitude (willingness, concerns) and practice(impacts on prescribing antibiotic behaviour, countermeasures to concerns) of doctors towards 2012 antimicrobial stewardship regulations; (4) doctors' knowledge of antimicrobial stewardship regulations and proper use of antimicrobials (question 30-32 originated from training examination questions for 'guiding principles for clinical application of antibacterial ${ }^{4}$ and administrative regulations for the clinical use of antimicrobials ${ }^{6}$ ). The questionnaire was about 18 phone screens long, which took $\sim 5 \mathrm{~min}$ to complete. We consulted 2 doctors and 1 methodologist and conducted a pilot survey with 10 doctors before starting the formal survey.

Data were imported from the survey website into Microsoft Excel 2016, then converted into the SPSS database. Statistical analysis was performed using IBM SPSS Statistics for Windows V.23.0. Descriptive statistics, Mann-Whitney test, $\chi^{2}$ test and multivariate regression were applied in description and analysis of the variables, where appropriate. Compulsory antimicrobial stewardship training, doctor's acceptance, impact on prescribing antibiotic behaviours, impact on prognosis of patients, concern and countermeasures towards the antimicrobial stewardship at the beginning of the implementation (2012) and 5 years after that (2016) were compared. Doctors 
with different educational background, levels of seniority, practicing organisations and geographic regions were considered as subgroups and compared. Logistic regression was used to screen factors relevant to knowledge of clinical use of antimicrobials.

Informed consent was obtained from all the participants. Participants were informed at the start of the survey about the length of time needed to complete the survey, the investigators and the purpose of the study. Participants were free to continue the survey or to quit at any time. Anonymous data were collected. No incentive was used to reward participants.

\section{Patient and public involvement}

No patient or public was involved in the design or planning of this study.

\section{RESULTS}

\section{Procedures}

The questionnaire was sent to 107 WeChat groups and 3 email groups that include 19791 health professionals (maximum number of potential reach). There were 3609 health professionals (actual reach) who clicked the web link of the questionnaire, out of whom 1194 completed the survey. Among the survey respondents, 807 were doctors; others were nurses, researchers, clinical postgraduates or administrative staffs.

\section{Demographics}

Data provided by doctors were collected and analysed. All 807 doctors fully completed the online survey (online supplementary table S3 and S4). Doctors had a mean age of 39.0years $(\mathrm{SD}=7.4)$, range 22-68. Men account for $41.3 \%$ of the total. More than $70 \%$ of doctors $(71.2 \%)$ had MSc, MD or PhD degree $(n=575)$. Most of them were residents or associated chief-physicians $(n=336$; $41.6 \%$ and $\mathrm{n}=241 ; 29.9 \%$, respectively). Approximately half $(n=386 ; 47.8 \%)$ of doctors majored in western medicine, others majored in traditional Chinese medicine or integrative medicine. $83.7 \%$ doctors started clinical practice before 2012. The number of outpatient services provided weekly was diverse, ranging from none $(22.8 \%$ and $15.4 \%$ in $2007-2011$ and 2012-2016, respectively) to 5 days $(18.7 \% ; 17.5 \%)$. Although almost half of doctors were from eastern China (49.2\%), there was also a good number from central, western and north-eastern China. About three in every five $(60.8 \%)$ of the doctors were working in first-tier and new first-tier cities (eg, Beijing, Shanghai and Hangzhou). Most doctors (79.8\%) worked in tertiary hospitals.

\section{Experiences of implementation of the antimicrobial stewardship regulations}

The clear majority of practitioners reported that hospital implementation of antimicrobial stewardship regulations was stringent $(45.1 \%)$ or very stringent $(45.7 \%)$ (table 1$)$. Specific training sessions were frequent or intensive in
$2012(59.1 \%)$ and in $2016(68.5 \%)(\mathrm{p}<0.001)$ (figure 1$)$. Practitioners from tertiary western medicine hospitals in first/new first-tier cities reported more stringent requirements for the implementation of the regulations (figure 2, online supplementary figure S1, S2 and S3). Doctors in departments of respiratory medicine, emergency medicine, paediatrics, intensive care, haematology and dentistry reported that they were permitted higher upper limits than the general limits of their hospitals. The largest gap in antimicrobial prescription limits was between respiratory departments $(33.5 \%)$ and hospitals overall, irrespective of departments $(22.4 \%)$.

\section{Knowledge of antimicrobial stewardship regulations and proper use of antimicrobials}

Although most doctors (65.1\%) declared that they were familiar or very familiar with the 2012 stewardship regulations, less than half answered the three-question knowledge test (question 30-32) correctly (46.8\%) (table 2). Doctors from primary care had a lower correct rate compared with those from other hospitals $(\mathrm{p}=0.013)$; doctors who majored in traditional Chinese medicine had a lower correct rate compared with those who majored in western/integrative medicine as measured in the multivariate regression equation $(p=0.001)$. The most commonly reported criteria for prescribing antimicrobials were full blood count $(94.2 \%)$, pathogen detection such as sputum or blood culture $(77.0 \%)$, symptoms $(72.9 \%)$, signs (71.4\%), $\mathrm{C}$ reactive protein (CRP) level $(62.9 \%)$ and the diagnosis $(60.5 \%)$.

\section{Attitudes towards implementation of the antimicrobial stewardship regulations}

In 2012, $78.9 \%$ of doctors reported that they were willing or very willing to accept the regulations, and the percentage increased to $89.1 \%$ in $2016(\mathrm{p}=0.002)$ (table 3). In 2012 and 2016, doctors who majored in western medicine reported lower acceptance rates $(74.6 \% ; 86.5 \%)$ than those who majored in Chinese medicine or integrative medicine $(82.9 \%$; $91.4 \%) .30 .0 \%$ of doctors reported the antimicrobial stewardship regulations had a moderate or large impact on the prognosis of these patients 'at risk' (means patients who would have been prescribed antimicrobials before the implementation of the 2012 stewardship regulations). Only $6.8 \%$ of doctors felt the stewardship regulations did not result in putting the prognosis of these patients at risk. More than $65 \%$ of doctors $(65.7 \%$ in $2012,66.9 \%$ in 2016 ; $p=0.367$ ) were 'often or always concerned' about the prognosis of patients at risk.

Doctors' practice of the antimicrobial stewardship regulations In 2012, 41.6\% of doctors reported that prescribing of antimicrobials had been very $(6.1 \%)$ or moderately $(35.5 \%)$ restricted during the implementation of antimicrobial stewardship regulations (table 3 ). The percentages even increased in 2016 (8.4\%; 38.9\%) (2016 vs 2012, $\mathrm{p}=0.019$ ). In $2012,32 \%$ of doctors stated that they had prescribed 
Table 1 Implementation of the antimicrobial stewardship regulations

\begin{tabular}{|c|c|c|c|c|c|c|c|c|c|c|}
\hline \multirow[b]{2}{*}{ Questions asked } & \multirow[b]{2}{*}{$\begin{array}{l}\text { Total } \\
\mathrm{n}=\mathbf{8 0 7}\end{array}$} & \multicolumn{3}{|c|}{ Medical organisation level } & \multicolumn{2}{|l|}{ City level } & \multicolumn{2}{|l|}{ Title } & \multicolumn{2}{|l|}{ Major } \\
\hline & & $\begin{array}{l}\text { Tertiary } \\
\mathrm{n}=644\end{array}$ & $\begin{array}{l}\text { Secondary } \\
n=112\end{array}$ & $\begin{array}{l}\mathrm{Pm} / \mathrm{Pv} \\
\mathrm{n}=51\end{array}$ & $\begin{array}{l}\text { 1/new } 1 / 2^{*} \\
\mathrm{n}=651\end{array}$ & $\begin{array}{l}\text { Others } \\
n=156\end{array}$ & $\begin{array}{l}\text { IT/RS } \\
n=443\end{array}$ & $\begin{array}{l}\text { ACP/ } \\
\text { CP } n=364\end{array}$ & $\begin{array}{l}\text { WM } \\
n=386\end{array}$ & $\begin{array}{l}\text { TCM/IM } \\
n=421\end{array}$ \\
\hline \multicolumn{11}{|c|}{ Medical organisation antimicrobial stewardship implementation \% } \\
\hline Very stringent & 45.7 & 50.6 & 33.0 & 11.8 & 47.9 & 36.5 & 44.2 & 47.5 & 50.0 & 41.8 \\
\hline Stringent & 45.1 & 44.1 & 50.0 & 47.1 & 44.2 & 48.7 & 45.1 & 45.1 & 44.0 & 46.1 \\
\hline Less stringent & 7.8 & 4.5 & 16.1 & 31.4 & 6.5 & 13.5 & 9.0 & 6.3 & 5.4 & 10.0 \\
\hline No & 1.4 & 0.8 & 0.9 & 9.8 & 1.4 & 1.3 & 1.6 & 1.1 & 0.5 & 2.1 \\
\hline \multicolumn{11}{|c|}{ Compulsory antimicrobial stewardship training in 2012 (first year of stewardship implementation) \% } \\
\hline Intensive & 9.7 & 10.9 & 6.3 & 3.9 & 11.4 & 2.7 & 8.3 & 11.4 & 11.1 & 8.4 \\
\hline Frequent & 49.4 & 52.4 & 41.4 & 31.4 & 50.6 & 44.5 & 47.6 & 51.4 & 50.0 & 48.8 \\
\hline Less frequent & 36.6 & 33.2 & 49.5 & 49.0 & 33.9 & 47.9 & 38.8 & 34.2 & 35.1 & 38.1 \\
\hline No & 4.2 & 3.5 & 2.7 & 15.7 & 4.1 & 4.8 & 5.3 & 3.1 & 3.8 & 4.6 \\
\hline Not applicable & $n=48$ & & & & & & & & & \\
\hline \multicolumn{11}{|c|}{ Compulsory antimicrobial stewardship training in 2016 \% } \\
\hline Intensive & 12.6 & 14.0 & 8.0 & 5.9 & 14.1 & 6.4 & 12.4 & 12.9 & 13.5 & 11.9 \\
\hline Frequently & 55.9 & 58.1 & 50.0 & 41.2 & 55.9 & 55.8 & 53.0 & 59.3 & 56.0 & 55.8 \\
\hline Less frequency & 28.6 & 26.4 & 38.4 & 35.3 & 27.0 & 35.3 & 30.5 & 26.4 & 28.0 & 29.2 \\
\hline No & 2.9 & 1.6 & 3.6 & 17.6 & 2.9 & 2.6 & 4.1 & 1.4 & 2.6 & 3.1 \\
\hline \multicolumn{11}{|c|}{$\%$ of all prescriptions which are permitted to contain antimicrobials (according to the hospital's internal policy) \% } \\
\hline$\leq 20$ & 59.8 & 60.1 & 44.4 & 86.0 & 65.6 & 39.7 & 62.0 & 57.5 & 47.7 & 72.0 \\
\hline $21-40$ & 32.9 & 33.3 & 43.2 & 9.3 & 29.8 & 43.7 & 31.5 & 34.4 & 43.8 & 22.0 \\
\hline $41-60$ & 6.5 & 5.9 & 12.3 & 2.3 & 4.1 & 15.1 & 5.5 & 7.7 & 7.8 & 5.3 \\
\hline$>60$ & 0.7 & 0.7 & 0.0 & 2.3 & 0.5 & 1.6 & 1.0 & 0.4 & 0.7 & 0.7 \\
\hline Not reported & $n=242$ & & & & & & & & & \\
\hline \multicolumn{11}{|c|}{$\%$ of all prescriptions which are permitted to contain antimicrobials (according to the department's internal policy) \% } \\
\hline$\leq 20$ & 64.1 & 64.1 & 51.9 & 86.0 & 69.5 & 45.2 & 65.4 & 62.6 & 53.7 & 74.5 \\
\hline $21-40$ & 26.5 & 26.6 & 34.2 & 11.6 & 23.5 & 37.3 & 24.3 & 28.9 & 34.3 & 18.8 \\
\hline $41-60$ & 8.0 & 7.4 & 13.9 & 2.3 & 6.2 & 14.3 & 8.2 & 7.7 & 9.5 & 6.4 \\
\hline$>60$ & 1.4 & 1.8 & 0.0 & 0.0 & 0.9 & 3.2 & 2.1 & 0.7 & 2.5 & 0.4 \\
\hline Not reported & $n=242$ & & & & & & & & & \\
\hline
\end{tabular}

*1/new1/2: first/new first/second-tier (first-tier city, such as Beijing, Shanghai; new first-tier city, such as Chengdu, Hangzhou; second-tier city, such as Shenyang, Xi'an).

ACP/CP, associate chief-physician/chief-physician; IT/RS, intern/resident; Pm/Pv, primary/private clinic; TCM/IM, traditional Chinese medicine/integrative medicine of traditional Chinese medicine and western medicine; WM, western medicine.

or suggested patient self-medication with restricted antimicrobials (restricted by the specific criteria for conditions in the stewardship) to address concerns for patients at risk (figure 1), but it decreased to $22.6 \%$ in 2016 (2016 vs 2012, $\mathrm{p}<0.001)$. In 2012, this prescribing behaviour was reportedly more common $(42.2 \%)$ in small cities, but in 2016 there no longer seemed to be any obvious difference between city levels. This behaviour was higher among doctors who majored in western medicine than among those who majored in traditional Chinese medicine or integrative medicine $(37.8 \%$ and $26.5 \%$, respectively, in $2012,24.3 \%$ and $20.9 \%$ in 2016). This proportion was higher among interns (44.6\% in 2012; $30.8 \%$ in 2016) than other doctors (30.7\% in 2012; 21.3 in 2016). More doctors prescribed permitted antimicrobials in 2016 than in $2012(46.7 \%, 43.8 \%)$ when treatment was needed. In 2012 and $2016,13.6 \%$ and $10.4 \%$ prescribed alternatives to antimicrobials; $95.8 \%(69 / 72)$ and $96.2 \%$ (102/106) of these prescribed traditional Chinese medicines.

\section{DISCUSSION}

\section{Summary of findings}

The data were collected from doctors in China with all medical education background, levels of seniority of the doctors, covering those who work in all levels of cities, types of medical organisations and levels of medical organisations (online supplementary table S3, S4). The 


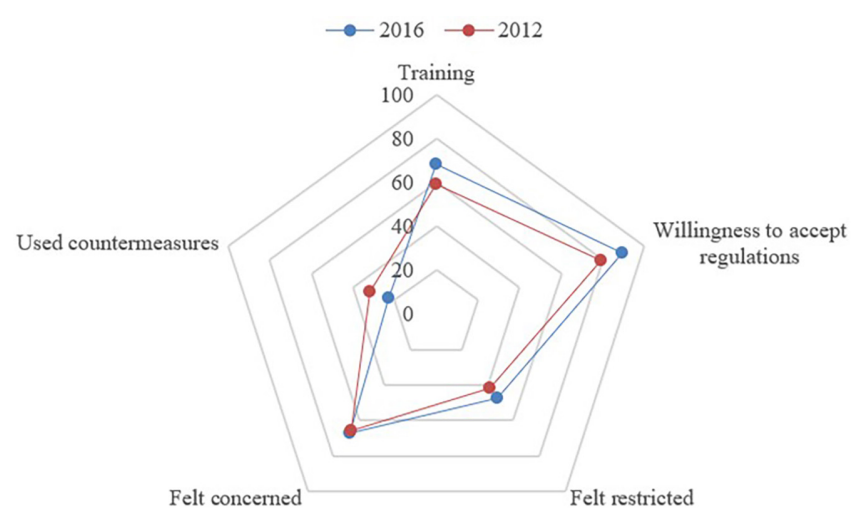

Figure 1 Attitudes and practice of doctors towards antimicrobial stewardship in 2012 and 2016. Percentage of doctors who: received intensive or frequent compulsory stewardship training; were willing or very willing to accept stewardship; felt restricted or very restricted by stewardship; felt often concerned or always concerned with the prognosis of patients 'at risk'; prescribed antimicrobials as before, or suggest patient self-medication with restricted antimicrobials as countermeasures.

data covered doctors from 29/32 administrative divisions of mainland China, representing nearly all regions of China. Although about half $(49.2 \%)$ of our respondents were based in Eastern China, this reflects the proportion of doctors in Eastern China, which accounts for about $43 \%$ of doctors in China. ${ }^{13}$ Since the respondents are those with higher educational background and work in higher level hospital level than average, their knowledge, attitudes, practice related to stewardship may be overestimated.

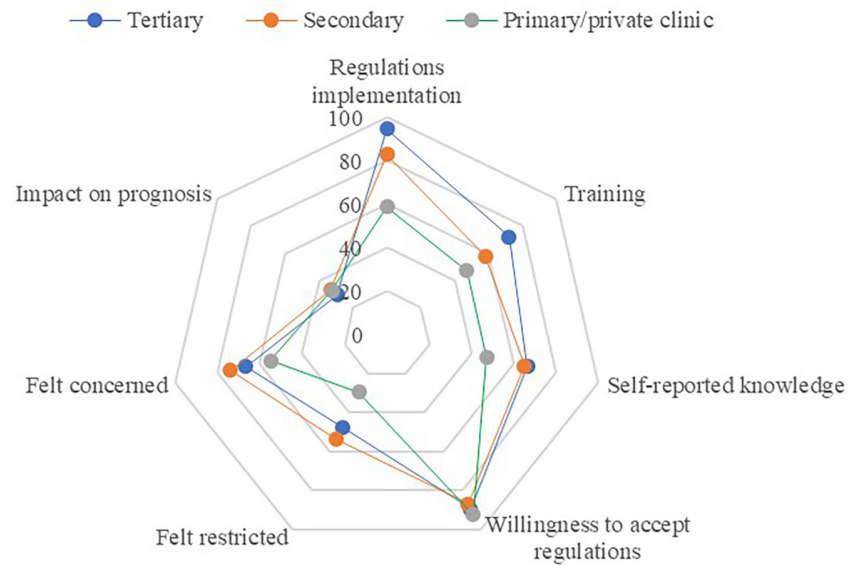

Figure 2 Knowledge, attitudes and practice of doctors towards antimicrobial stewardship in different medical organisation levels in 2016. Percentage of doctors who: worked in a medical organisation with stringent or very stringent stewardship regulations implementation; received intensive or frequent compulsory stewardship training; described themselves as familiar or very familiar with stewardship; were willing or very willing to accept stewardship; felt restricted or very restricted by stewardship; felt often concerned or always concerned with the prognosis of patients 'at risk'; felt stewardship has a moderate or strong impact on prognosis of patients at risk.
The implementation of the 2012 stewardship regulations was considered stringent. The percentage of all prescriptions which are permitted to contain antimicrobials in respiratory departments was set to be high by the answers from the doctors, with an average of $33.5 \%$. Insufficient knowledge on proper use of antimicrobials was obvious, especially in primary medical organisations. Most doctors (94.2\%) used full blood count as the criterion for prescribing antimicrobials. Compulsory stewardship training and willingness to accept the stewardship regulations increased from 2012 to 2016. Due to restricted prescription of antimicrobials, doctors' concerns with prognosis of patients at risk remained high. It seems that the use of restricted antimicrobials has greatly reduced, but the use of permitted antimicrobials may have increased. Traditional Chinese medicine may have played a role as an alternative to antimicrobials.

\section{Strengths and limitations}

To the best of our knowledge, this is the first survey in China to comprehensively explore doctors' feelings and attitudes towards the Chinese antimicrobial stewardship regulations. We recruited participants and administered the survey via WeChat (one of the most common social APPs in China). It is a convenient, time-saving and economic method to survey a diverse population. Our respondents covered 29 of 32 administrative divisions of mainland China. Despite this, our study has a number of limitations. First, we cannot rule out a possible selection bias as our sample was not randomly selected. Although the snowball sampling method is effective and efficient when sampling from specific populations, participants who can be reached depend on the social connections of the key respondents. Also, doctors in primary care settings or private clinics are less likely to belong to any academic association or doctors' group, thus they may be less likely to be reached. According to the data of the Chinese government, ${ }^{13}$ the percentage of doctors in primary care settings and private clinics are about $4.3 \%$ and $11.4 \%$ in China in 2016, respectively. In this survey, doctors in primary care settings and private clinics accounted for $5.0 \%$ and $1.4 \%$ of respondents, respectively. In addition, the use of clinician's WeChat groups by researchers for first invitations may also be one of the reasons for potential bias. Our professional connections are more likely to be similar to ourselves. In order to overcome this potential bias, we invited our first-round invitation receivers to send our links to their own clinician connections. This may have helped to correct the selection bias that relate to our first invitation receivers. We also invited members of academic associations in our first invitations and most of the members of those associations are usually academic clinicians. In China, about $80 \%$ of the clinicians work in public hospitals, ${ }^{13}$ conducting or participating in academic research is a requirement for them. Most of the clinicians need to work both clinically and academically. Second, the proportion of completed questionnaires to all potential responders is low $(6.0 \%, 1194 / 19$ 
Table 2 Knowledge of antimicrobial stewardship

\begin{tabular}{|c|c|c|c|c|c|c|c|c|c|c|}
\hline \multirow[b]{2}{*}{$\begin{array}{l}\text { Questions } \\
\text { asked }\end{array}$} & \multirow[b]{2}{*}{$\begin{array}{l}\text { Total } \\
\mathrm{n}=807\end{array}$} & \multicolumn{3}{|c|}{ Medical organisation level } & \multicolumn{2}{|l|}{ City level } & \multicolumn{2}{|l|}{ Title } & \multicolumn{2}{|l|}{ Major } \\
\hline & & $\begin{array}{l}\text { Tertiary } \\
\mathrm{n}=644\end{array}$ & $\begin{array}{l}\text { Secondary } \\
n=112\end{array}$ & $\begin{array}{l}\mathrm{Pm} / \mathrm{Pv} \\
\mathrm{n}=51\end{array}$ & $\begin{array}{l}1 / \text { new } 1 / 2^{*} \\
n=651\end{array}$ & $\begin{array}{l}\text { Others } \\
n=156\end{array}$ & $\begin{array}{l}\text { IT/RS } \\
n=443\end{array}$ & $\begin{array}{l}\text { ACP/ } \\
\text { CP } n=364\end{array}$ & $\begin{array}{l}\text { WM } \\
n=386\end{array}$ & $\begin{array}{l}\text { TCM/IM } \\
\mathrm{n}=421\end{array}$ \\
\hline \multicolumn{11}{|c|}{ Self-reported knowledge of antimicrobial stewardship \% } \\
\hline Very familiar & 16.1 & 17.1 & 12.5 & 11.8 & 16.9 & 12.8 & 10.6 & 22.8 & 18.9 & 13.5 \\
\hline Familiar & 48.9 & 49.4 & 52.7 & 35.3 & 48.8 & 49.4 & 44.0 & 54.9 & 47.2 & 50.6 \\
\hline Know a little & 31.0 & 30.0 & 32.1 & 41.2 & 30.0 & 35.3 & 39.5 & 20.6 & 30.3 & 31.6 \\
\hline Do not know & 4.0 & 3.6 & 2.7 & 11.8 & 4.3 & 2.6 & 5.9 & 1.6 & 3.6 & 4.3 \\
\hline
\end{tabular}

Tested results of knowledge of antimicrobial prescribing

Which surgery should apply perioperative antimicrobial prophylaxis

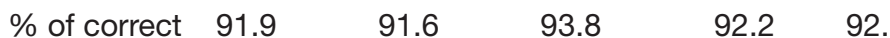

$\begin{array}{lllll}89.7 & 92.3 & 91.5 & 92.2 & 91.7\end{array}$

Which antimicrobial should be used for extended-spectrum $\beta$-lactamases-producing bacterial infection

$\begin{array}{lllllllllll}\text { \% of correct } & 70.5 & 72.1 & 74.1 & 43.1 & 69.3 & 75.6 & 65.2 & 76.9 & 78.2 & 63.4\end{array}$

For how long a restricted antibiotic can be used in emergent medical situations

$\begin{array}{lllllllllll}\% \text { of correct } & 66.7 & 67.7 & 72.3 & 41.2 & 66.1 & 69.2 & 64.3 & 69.5 & 72.3 & 61.5\end{array}$

Criteria for prescribing antimicrobials (multiple choice) $\%$

\begin{tabular}{lllllllllll} 
Symptom & 72.9 & 75.9 & 67.9 & 45.1 & 72.4 & 75.0 & 74.3 & 71.2 & 75.6 & 70.3 \\
Sign & 71.4 & 73.6 & 70.5 & 45.1 & 70.8 & 74.4 & 71.1 & 71.7 & 72.8 & 70.1 \\
$\begin{array}{l}\text { Full blood } \\
\text { count }\end{array}$ & 94.2 & 95.0 & 92.0 & 88.2 & 95.4 & 89.1 & 95.0 & 93.1 & 92.7 & 95.5 \\
CRP & 62.9 & 64.0 & 59.8 & 56.9 & 62.2 & 66.0 & 61.9 & 64.3 & 61.7 & 64.1 \\
PD & 77.0 & 83.2 & 65.2 & 23.5 & 92.0 & 78.2 & 75.4 & 78.8 & 84.2 & 70.3 \\
Diagnosis & 60.5 & 62.9 & 58.9 & 33.3 & 60.7 & 59.6 & 58.9 & 62.4 & 68.9 & 52.7 \\
Others & 18.2 & 19.3 & 14.3 & 13.7 & 18.7 & 16.0 & 17.8 & 18.7 & 21.5 & 15.2 \\
\hline
\end{tabular}

*1/new1/2: first/new first/second-tier (first-tier city, such as Beijing, Shanghai; new first-tier city, such as Chengdu, Hangzhou; second-tier city, such as Shenyang, Xi'an).

ACP/CP, associate chief-physician/chief-physician; CRP, C reactive protein; IT/RS, intern/resident; PD, pathogen detection; Pm/Pv, primary/ private clinic; TCM/IM, traditional Chinese medicine/integrative medicine of traditional Chinese medicine and western medicine; WM, western medicine.

791), similar to the other web-based surveys. ${ }^{14}{ }^{15}$ Nineteen thousand seven hundred and ninety-one is the sum of people in all the WeChat groups. This is the maximum number of people that potentially can be reached by us. There is no way to collect the number of people who saw the link but choose to ignore it. The number of people who clicked the link is an important parameter that we can achieve. Three thousand six hundred and eighteen people clicked the link and 1194 completed it $(33.0 \%$, $1194 / 3618)$. Another limitation is the potential recall bias of information provided for year 2012 and 2016.

\section{Comparisons with other studies}

We did not identify any studies investigating the attitudes of doctors towards the 2012 antimicrobial stewardship regulations. Doctors' willingness and concerns might impact on their prescribing behaviours and weaken the effects of the regulations. We found in our study that the knowledge about proper use of antimicrobials of doctors from primary care clinics or private clinics seems insufficient. Similar results were reported from three surveys (sample sizes $761,180,611$ ) focusing on doctors' or trainees' knowledge and continued education. ${ }^{16-18}$ In our study, doctors reported that they recommended self-medication of restricted antimicrobials to address concerns for patients at risk. Another survey of 256 pharmacies in three Chinese cities ${ }^{19}$ showed that antibiotics were obtained without a prescription from $77.7 \%$ pharmacies for adult respiratory infections. In our study, the percentage of all prescriptions which are permitted to contain antimicrobials in respiratory departments was very high. A survey of 1204 people in three Chinese cities ${ }^{20}$ showed that cough, sore throat and bronchitis were the most frequent reasons reported for antibiotic use. This is also consistent with the situation in the $\mathrm{UK}^{21}$

In our study, full blood count (raised white blood cell counts and increased proportion of neutrophilic granulocytes) was overwhelmingly considered as the main criterion for prescribing antimicrobials. This medical behaviour is in accordance with the Chinese acute bronchitis clinical practice guidelines, ${ }^{22}{ }^{23}$ which state that oral antibiotics such as $\beta$-lactams and fluoroquinolones can be used in patients with cough before the pathogen 
Table 3 Attitudes and practice of doctors towards the antimicrobial stewardship regulations in 2012 and 2016

\begin{tabular}{|c|c|c|c|c|c|c|c|c|c|c|}
\hline \multirow[b]{2}{*}{ Questions asked } & \multirow[b]{2}{*}{$\begin{array}{l}\text { Total } \\
\mathrm{n}=\mathbf{8 0 7}\end{array}$} & \multicolumn{3}{|c|}{ Medical organisation level } & \multicolumn{2}{|l|}{ City level } & \multicolumn{2}{|l|}{ Title } & \multicolumn{2}{|l|}{ Major } \\
\hline & & $\begin{array}{l}\text { Tertiary } \\
\mathrm{n}=644\end{array}$ & $\begin{array}{l}\text { Secondary } \\
n=112\end{array}$ & $\begin{array}{l}\mathrm{Pm} / \mathrm{Pv} \\
\mathrm{n}=51\end{array}$ & $\begin{array}{l}1 / \text { new } 1 / 2^{*} \\
n=651\end{array}$ & $\begin{array}{l}\text { Others } \\
n=156\end{array}$ & $\begin{array}{l}\text { IT/RS } \\
n=443\end{array}$ & $\begin{array}{l}\text { ACP/CP } \\
n=364\end{array}$ & $\begin{array}{l}\text { WM } \\
n=386\end{array}$ & $\begin{array}{l}\text { TCM/IM } \\
\mathrm{n}=421\end{array}$ \\
\hline \multicolumn{11}{|c|}{ Personal willingness to accept antimicrobial stewardship regulations in 2012 (first year of implementation) \% } \\
\hline Very willing & 26.5 & 26.3 & 18.9 & 45.8 & 28.4 & 18.6 & 27.9 & 25.1 & 24.0 & 28.8 \\
\hline Willing & 52.4 & 52.6 & 52.8 & 47.9 & 53.3 & 48.6 & 49.7 & 55.2 & 50.6 & 54.0 \\
\hline Hard to accept & 19.2 & 19.0 & 26.4 & 6.3 & 16.4 & 31.4 & 20.6 & 17.7 & 23.2 & 15.6 \\
\hline Unacceptable & 1.9 & 2.1 & 1.9 & 0.0 & 2.0 & 1.4 & 1.8 & 2.0 & 2.3 & 1.6 \\
\hline Not applicable & $\mathrm{n}=68$ & & & & & & & & & \\
\hline \multicolumn{11}{|c|}{ Personal willingness to accept antimicrobial stewardship regulations in $2016 \%$} \\
\hline Very willing & 27.4 & 28.4 & 17.0 & 37.3 & 27.6 & 26.3 & 24.2 & 31.3 & 25.9 & 28.7 \\
\hline Willing & 61.7 & 60.9 & 69.6 & 54.9 & 61.9 & 60.9 & 64.3 & 58.5 & 60.6 & 62.7 \\
\hline Hard to accept & 10.0 & 9.8 & 13.4 & 5.9 & 9.5 & 12.2 & 10.6 & 9.3 & 12.2 & 8.1 \\
\hline Unacceptable & 0.9 & 0.9 & 0.0 & 2.0 & 0.9 & 0.6 & 0.9 & 0.8 & 1.3 & 0.5 \\
\hline
\end{tabular}

Impact of antimicrobial stewardship on prescribing antibiotic behaviours in 2012 (first year of implementation) \%

\begin{tabular}{lrrrrrrrrrr} 
Very restricted & 6.1 & 6.2 & 5.6 & 6.1 & 6.0 & 6.3 & 7.0 & 5.1 & 7.0 & 5.2 \\
\hline Restricted & 35.5 & 36.9 & 35.5 & 18.4 & 35.7 & 34.7 & 37.4 & 33.4 & 35.9 & 35.1 \\
\hline Slightly & 48.3 & 48.0 & 46.7 & 55.1 & 48.2 & 48.6 & 45.5 & 51.4 & 49.0 & 47.6 \\
\hline Not restricted & 10.1 & 8.9 & 12.1 & 20.4 & 10.1 & 10.4 & 10.1 & 10.1 & 8.1 & 12.0
\end{tabular}

Impact of antimicrobial stewardship on prescribing antimicrobial behaviours in $2016 \%$

$\begin{array}{lrrrrrrrrrr}\text { Very restricted } & 8.4 & 8.5 & 9.8 & 3.9 & 8.0 & 10.3 & 7.4 & 9.6 & 10.6 & 6.4 \\ \text { Restricted } & 38.9 & 39.1 & 43.8 & 25.5 & 38.2 & 41.7 & 43.1 & 33.8 & 41.2 & 36.8 \\ \text { Slightly } & 43.5 & 43.6 & 40.2 & 49.0 & 44.2 & 40.4 & 41.5 & 45.9 & 40.7 & 46.1 \\ \text { Not restricted } & 9.2 & 8.7 & 6.3 & 21.6 & 9.5 & 7.7 & 7.9 & 10.7 & 7.5 & 10.7\end{array}$

Concerns with prognosis of patients 'at risk' -who would have been given antimicrobials before the stewardship in 2012 (first year of implementation) \%

$\begin{array}{lrrrrrrrrrr}\text { Always } & 16.8 & 17.1 & 19.3 & 8.3 & 13.9 & 29.2 & 18.5 & 15.0 & 19.7 & 14.1 \\ \text { Often } & 48.9 & 48.0 & 51.4 & 54.2 & 50.9 & 40.3 & 49.1 & 48.6 & 50.8 & 47.0 \\ \text { Sometimes } & 29.9 & 30.2 & 27.5 & 31.3 & 30.1 & 29.2 & 27.2 & 32.8 & 25.3 & 34.2 \\ \text { No } & 4.4 & 4.8 & 1.8 & 6.3 & 5.2 & 1.4 & 5.1 & 3.7 & 4.2 & 4.7 \\ \text { Not applicable } & \mathrm{n}=64 & & & & & & & & & \end{array}$

Concerns with prognosis of patients at risk in $2016 \%$

\begin{tabular}{|c|c|c|c|c|c|c|c|c|c|c|}
\hline Always & 12.6 & 12.7 & 16.1 & 3.9 & 11.5 & 17.3 & 14.7 & 10.2 & 14.5 & 10.9 \\
\hline Often & 54.3 & 53.9 & 58.0 & 51.0 & 53.3 & 58.3 & 54.9 & 53.6 & 56.2 & 52.5 \\
\hline Sometimes & 26.8 & 26.9 & 22.3 & 35.3 & 28.3 & 20.5 & 24.6 & 29.4 & 24.1 & 29.2 \\
\hline No & 6.3 & 6.5 & 3.6 & 9.8 & 6.9 & 3.8 & 5.9 & 6.9 & 5.2 & 7.4 \\
\hline
\end{tabular}

Impact of antimicrobial stewardship on prognosis of patients at risk \%

\begin{tabular}{lrrrrrrrrrrr} 
Strong & 2.4 & 2.3 & 1.8 & \multicolumn{1}{c}{3.} & 2.5 & 1.9 & 2.3 & 2.5 & 2.6 & 2.1 \\
Moderate & 27.6 & 26.9 & 31.3 & 29.4 & 27.0 & 30.1 & 31.8 & 22.5 & 27.7 & 27.6 \\
Slight & 63.2 & 64.1 & 61.6 & 56.9 & 63.3 & 62.8 & 59.6 & 67.6 & 63.5 & 62.9 \\
No & 6.8 & 6.8 & 5.4 & 9.8 & 7.2 & 5.1 & 6.3 & 7.4 & 6.2 & 7.4
\end{tabular}

Countermeasures to concerns for prognosis of patients at risk in 2012 (first year of implementation) \%

\begin{tabular}{lrrrrrrrrrr} 
Countermeasures to concerns for prognosis of patients at risk in 2012 (first year of implementation) \% \\
AB & 16.8 & 16.9 & 18.3 & 11.1 & 16.4 & 18.3 & 17.9 & 15.5 & 20.3 & 13.4 \\
OM & 43.8 & 43.8 & 41.3 & 48.9 & 46.0 & 34.5 & 47.6 & 39.7 & 41.8 & 45.6 \\
\hline & 10.4 & 10.8 & 7.7 & 11.1 & 10.2 & 11.3 & 7.5 & 13.5 & 4.0 & 16.4 \\
\hline
\end{tabular}


Table 3 Continued

\begin{tabular}{|c|c|c|c|c|c|c|c|c|c|c|}
\hline \multirow[b]{2}{*}{ Questions asked } & \multirow[b]{2}{*}{$\begin{array}{l}\text { Total } \\
n=807\end{array}$} & \multicolumn{3}{|c|}{ Medical organisation level } & \multicolumn{2}{|l|}{ City level } & \multicolumn{2}{|l|}{ Title } & \multicolumn{2}{|l|}{ Major } \\
\hline & & $\begin{array}{l}\text { Tertiary } \\
n=644\end{array}$ & $\begin{array}{l}\text { Secondary } \\
n=112\end{array}$ & $\begin{array}{l}\mathrm{Pm} / \mathrm{Pv} \\
\mathrm{n}=51\end{array}$ & $\begin{array}{l}\text { 1/new1/2* } \\
n=651\end{array}$ & $\begin{array}{l}\text { Others } \\
n=156\end{array}$ & $\begin{array}{l}\text { IT/RS } \\
n=443\end{array}$ & $\begin{array}{l}\text { ACP/CP } \\
n=364\end{array}$ & $\begin{array}{l}\text { WM } \\
n=386\end{array}$ & $\begin{array}{l}\text { TCM/IM } \\
\mathrm{n}=421\end{array}$ \\
\hline No measures & 13.9 & 14.3 & 10.6 & 15.6 & 14.3 & 12.0 & 12.0 & 15.8 & 16.3 & 11.5 \\
\hline Not applicable & $\mathrm{n}=85$ & & & & & & & & & \\
\hline$A B$ & 9.7 & 9.8 & 9.8 & 7.8 & 10.1 & 7.7 & 11.1 & 8.0 & 10.6 & 8.8 \\
\hline AA & 46.7 & 46.1 & 50.0 & 47.1 & 46.4 & 48.1 & 50.8 & 41.8 & 48.2 & 45.4 \\
\hline OM & 13.6 & 13.0 & 13.4 & 21.6 & 13.8 & 12.8 & 9.9 & 18.1 & 6.0 & 20.7 \\
\hline SA & 12.9 & 13.4 & 10.7 & 11.8 & 11.7 & 17.9 & 12.2 & 13.7 & 13.7 & 12.1 \\
\hline No measures & 17.1 & 17.7 & 16.1 & 11.8 & 18.0 & 13.5 & 16.0 & 18.4 & 21.5 & 13.1 \\
\hline
\end{tabular}

*1/new1/2: first/new first/second-tier (first-tier city, such as Beijing, Shanghai; new first-tier city, such as Chengdu, Hangzhou; second -tier city, such as Shenyang, Xi'an).

$A A$, prescribe allowable antimicrobials; $A B$, prescribe the antimicrobials as before; ACP/CP, associate chief-physician/chief-physician; IT/RS, intern/resident; OM, prescribe other medicine (except antimicrobials); Pm/Pv, p/private clinic; SA, suggest patient-self-medication (to buy by themselves somewhere else) with intended antimicrobials restricted by the stewardship regulations; TCM/IM, traditional Chinese medicine/ integrative medicine of traditional Chinese medicine and western medicine; WM, western medicine.

detection results were available, if there are signs of purulent sputum or raised white cell counts (adults usually $>10 \times 10^{9} / \mathrm{L}$ ). However, it has been suggested by international guidelines that doctors should not perform testing or initiate antibiotic therapy in people with acute bronchitis (pneumonia excluded) ${ }^{24}$ Studies ${ }^{25}{ }^{26}$ have shown that blood tests do not accurately differentiate between bacterial and viral infections. In our survey, many doctors also reported using raised CRP as a criterion for prescribing antimicrobials. CRP may be helpful in adults and is recommended in the NICE (The National Institute for Health and Care Excellence) guidelines ${ }^{27}$ to be considered if antibiotics are being considered for treatment of lower respiratory tract infections. A study has shown that use of CRP can reduce antibiotic consumption in acute respiratory tract infections. ${ }^{28}$ However, Lemiengre and colleagues performed a cluster-randomised trial in 2227 children showing that CRP tests did not reduce antibiotic prescribing for non-severe acute infections in children in primary care and cannot be recommended..$^{29}$ In our survey, doctors with a traditional Chinese medicine/ integrative medicine background felt less restricted and were more willing to accept the stewardship regulations. Traditional Chinese medicines served as alternatives to antimicrobials for doctors. Similarly, in the UK, a retrospective study which included 7283 general practice (GP) surgeries suggested that GPs additionally trained in integrative medicine or complementary and complementary medicine had lower antibiotic prescribing rates compared with conventional GPs. ${ }^{30}$

\section{Implications for doctors and policymakers}

The implementation of the antimicrobial stewardship regulations requires administrative persistence and strengthened training of doctors on the use of antimicrobials, especially for primary care doctors. In addition to the mandatory administrative implementation, explanation of reasons why there is a need for proper use of antimicrobials and how to achieve it, as well as approaches to facilitate evidence-based clinical practicing are needed to guide clinical practice and to relieve doctors' concerns. The common practice of prescribing antimicrobials according to elevated full blood count or CRP is controversial. Although both guidelines and the stewardship regulations mentioned this, no threshold was defined. Suggested patient self-medication with restricted antimicrobials may have diminished the effect of the antimicrobial stewardship regulations. The increase in the use of permitted antimicrobials may be associated with inappropriate use, which is also an important cause of antimicrobial resistance. More stringent measures should be applied to stop antimicrobial purchase without prescriptions from retail pharmacies. Traditional Chinese medicine can be considered for relieving symptoms, complementing or replacing antimicrobials. ${ }^{31}$

\section{Future research}

First, there is a need for qualitative research to explore antibiotic prescribing behaviours in China, potential concerns from doctors and pharmacists, why there were differences between doctors in different types of hospitals/regions/major, and which intervention(s) would be most acceptable in their context to reduce antimicrobial prescribing. Then, we also suggest that a large representative sample cohort study or registry study in China is warranted, to explore the possibility of delayed antimicrobials or other antimicrobial replacement therapy from the perspectives of clinical effect, safety, reducing resistance and health economics. There is a need for more evidence to back up recommendations, 
particularly on (1) diagnostic and prognostic accuracy of various markers, for example, white cell counts and CRP; (2) prognosis of infections for which antibiotics were commonly prescribed; (3) guidelines and recommendations on when to use antibiotics. Additionally, we need to find other interventions that can relieve symptoms, complement or substitute antimicrobials, and then conduct high quality, large scale randomised controlled trials to validate their efficacy, effectiveness and safety. Traditional Chinese medicine is widely used in medical practice in China. ${ }^{32}$ We propose more clinical or basic research to explore which traditional Chinese medicine can be recommended instead of antibiotics for different infections.

\section{CONCLUSION}

In summary, the 2012 antimicrobial stewardship regulations improved proper clinical use of antimicrobials in China. Attitudes and behaviours of doctors towards the stewardship regulations improved from 2012 to 2016. Concerns about the prognosis of patients at risk were still prevalent, and doctors found ways of accessing antibiotics which undermined the implementation of the antimicrobial stewardship regulations. There is a gap between doctors in small cities and first-tier cities in terms of implementation of antimicrobial stewardship regulations and knowledge about proper use of antimicrobials.

\section{Author affiliations}

${ }^{1}$ Centre for Evidence-Based Chinese Medicine, Beijing University of Chinese Medicine, Beijing, China

${ }^{2}$ Primary Care and Population Sciences, University of Southampton, Southampton, UK

${ }^{3}$ Department of International Liaison, World Federation of Chinese Medicine Societies, Beijing, China

${ }^{4}$ Department of endocrinology, South of Guang'anmen Hospital, China Academy of Chinese Medical Sciences, Beijing, China

${ }^{5}$ Department of Neurology, The Affiliated Hospital of Changchun University of Chinese Medicine, Changchun, China

Acknowledgements We would like to thank all the participants who completed the survey. We are grateful to the key respondents, who circulated the survey link to doctor's WeChat groups.

Contributors RX, JL and YF conceived and designed the study. RX, Xinxue Li, $\mathrm{YL}, \mathrm{JW}$ and $\mathrm{YF}$ collected the data. RX and YF analysed the data and prepared the manuscript. XH, MW, MM, Xun Li and YF contributed to the interpretation of the results and critical revision of manuscript. All authors approved the final manuscript.

Funding This work was supported by the Key project of the National Natural Science Foundation of China (No.81830115) and the Fundamental Research Funds for the Central Universities (Beijing University of Chinese Medicine, 2017-JYB-JS-149).

\section{Competing interests None declared.}

Patient consent for publication Not required.

Ethics approval This study was approved by the ethical committee of Beijing University of Chinese Medicine (2017BZHYLL0201).

Provenance and peer review Not commissioned; externally peer reviewed. Data sharing statement № additional data are available.

Open access This is an open access article distributed in accordance with the Creative Commons Attribution Non Commercial (CC BY-NC 4.0) license, which permits others to distribute, remix, adapt, build upon this work non-commercially, and license their derivative works on different terms, provided the original work is properly cited, appropriate credit is given, any changes made indicated, and the use is non-commercial. See: http://creativecommons.org/licenses/by-nc/4.0/.

\section{REFERENCES}

1. WHO. The evolving threat of antimicrobial resistance: options for action. Geneva: World Health Organisation, 2012. http://www.who. int/iris/handle/10665/44812.

2. Hu F, Zhu D, Wang F, et al. Results from the Survey of Antibiotic Resistance (SOAR) 2009-11 and 2013-14 in China. J Antimicrob Chemother 2016;71(Suppl 1):i33-i43.

3. Zhang QQ, Ying GG, Pan CG, et al. Comprehensive evaluation of antibiotics emission and fate in the river basins of China: source analysis, multimedia modeling, and linkage to bacterial resistance. Environ Sci Technol 2015;49:6772-82.

4. National Health and Family Planning Commission of the People's Republic of China. Guiding principles for clinical application of antibacterial. 2015. http://www.nhfpc.gov.cn/yzygj/s3593/201508/ c18e1014de6c45ed9f6f9d592b43db42.shtml

5. National Health and Family Planning Commission of the People's Republic of China. Special Remediation activities for Antimicrobial Clinical use in China. 2013. http://www.nhfpc.gov.cn/mohyzs/s3585/ 201305/6042979f05cf49609e96410d7314ecae.shtml

6. National Health and Family Planning Commission of the People's Republic of China. Administrative regulations for the clinical use of antimicrobials. 2012. http://www.moh.gov.cn/mohyzs/s3584/201205/ 54645.shtml

7. National Health and Family Planning Commission of the People's Republic of China. Plan of national action for curb bacterial resistance (2016-2020). 2016. http://www.nhfpc.gov.cn/yzygj/s3593/ 201608/f1ed26a0c8774e1c8fc89dd481ec84d7.shtml

8. Huang YB, Zd L, Zeng ST. Investigation on Application of Antibiotics in Department of Respiration in Guangxi Zhuang Autonomous Region Nanxishan Hospital during 2010-2014. Evaluation and Analysis of Drug-Use in Hospitals of China 2016;3:372-5.

9. Chen SC, Sun WF, Hy L, et al. Analysis of the Effects of Antibacterial Special Rectification Activities in Tertiary Hospitals of Six Regions as Beijing. China Pharmacy 2015;29:4041-4.

10. $\mathrm{Li} \mathrm{H}$. Analysis of clinical efficacy of antibiotics for patients in respiratory department. Frontier health 2016;6:127.

11. Jao N. WeChat now has over 1 billion active monthly users worldwide. 2018. https://technode.com/2018/03/05/wechat-1-billionusers/

12. Brislin WR. Back-Translation for Cross-Cultural Re- search. J CrossCult Psychol 1970;3:185-216.

13. National Health and Family Planning Commission of the People's Republic of China. China Statistical Yearbook on Health and Family Planning 2017. Beijing, BJ: Peking Union Medical College Press 2017:26-47.

14. Martens J, de Jong G, Rovers M, et al. Importance and Presence of High-Quality Evidence for Clinical Decisions in Neurosurgery: International Survey of Neurosurgeons. Interact J Med Res 2018;7:e16

15. Dai JC, Brisbane WG, Chang HC, et al. Anaphylactoid Reactions After Instillation of Contrast Material Into the Urinary Tract: A Survey of Contemporary Practice Patterns and Review of the Literature. Urology 2018;122:58-63.

16. Sun Q, Dyar OJ, Zhao L, et al. Overuse of antibiotics for the common cold - attitudes and behaviors among doctors in rural areas of Shandong Province, China. BMC Pharmacol Toxicol 2015;16.6:6.

17. Yang K, Wu D, Tan F, et al. Attitudes and perceptions regarding antimicrobial use and resistance among medical students in Central China. Springerplus 2016;5:5.

18. Bai $Y$, Wang S, Yin X, et al. Factors associated with doctors' knowledge on antibiotic use in China. Sci Rep 2016;6:23429.

19. Chang J, Ye D, Lv B, et al. Sale of antibiotics without a prescription at community pharmacies in urban China: a multicentre crosssectional survey. J Antimicrob Chemother 2017;72:dkw519-1242.

20. Ye D, Chang J, Yang C, et al. How does the general public view antibiotic use in China? Result from a cross-sectional survey. Int $J$ Clin Pharm 2017;39:927-34.

21. Smith DRM, Dolk FCK, Pouwels KB, et al. Defining the appropriateness and inappropriateness of antibiotic prescribing in primary care. J Antimicrob Chemother 2018;73:ii11-ii18.

22. Committee A, Society R. Chinese Medical Association. Guidelines for diagnosis and treatment of cough (2009). Chinese Journal of Tuberculosis and Respiratory Diseases 2009;6:407-13. 
23. Committee A, Society R. Chinese Medical Association. GUidelines for diagnosis and treatment of cough (2015). Chinese Journal of Tuberculosis and Respiratory Diseases 2016;5:323-54.

24. Harris AM, Hicks LA, Qaseem A. High Value Care Task Force of the American College of Physicians and for the Centers for Disease Control and Prevention. Appropriate antibiotic use for acute respiratory tract infection in adults: Advice for high-value care from the american college of physicians and the centers for disease control and prevention. Ann Intern Med 2016;164:425-34.

25. Liu X, Tong X, Jin L, et al. Prospective study on the overuse of blood test-guided antibiotics on patients with acute diarrhea in primary hospitals of China. Patient Prefer Adherence 2017;11:537-45.

26. Purcell K, Fergie J. Lack of usefulness of an abnormal white blood cell count for predicting a concurrent serious bacterial infection in infants and young children hospitalized with respiratory syncytial virus lower respiratory tract infection. Pediatr Infect Dis $J$ 2007;26:311-5.

27. National Institute for Health and Care Excellence (NICE). Pneumonia in adults: diagnosis and management. 2014. https://www.nice.org. uk/guidance/cg191

28. Little P, Stuart B, Francis N, et al. Effects of internet-based training on antibiotic prescribing rates for acute respiratory-tract infections: a multinational, cluster, randomised, factorial, controlled trial. Lancet 2013;382:1175-82.

29. Lemiengre MB, Verbakel JY, Colman R, et al. Reducing inappropriate antibiotic prescribing for children in primary care: a cluster randomised controlled trial of two interventions. $\mathrm{Br} J$ Gen Pract 2018;68:e204-e210.

30. van der Werf ET, Duncan LJ, Flotow PV, et al. Do NHS GP surgeries employing GPs additionally trained in integrative or complementary medicine have lower antibiotic prescribing rates? Retrospective cross-sectional analysis of national primary care prescribing data in England in 2016. BMJ Open 2018;8:e20488.

31. Xia RY, Xy H, Wang D, et al. Evidence base of randomized controlled trials and guideline recommendations of patent Traditional Chinese Medicines for uncomplicated acute lower respiratory tract infections in adults. $J$ Tradit Chin Med 2018;4:490-503.

32. The State Council Information Office of the People's Republic of China. III. Carrying Forward the Tradition and Ensuring the Development of TCM. Traditional Chinese Medicine in China 2017 http://www.china.org.cn/chinese/2017-01/17/content_40120942_5. htm. 